\title{
Development and Characterization of Hybrid Composite using Pineapple and Glass Fibers
}

\author{
Chiranth S C ${ }^{1}$, Keerthiprasad K S ${ }^{2}$, Sandeep B ${ }^{3}$ \\ P G Student, Vidya Vikas Institute of Engineering \& Technology, Mysuru \\ Professor, Vidya Vikas Institute of Engineering \& Technology, Mysuru \\ Asst. Professor, Vidya Vikas Institute of Engineering \& Technology, Mysuru
}

\begin{abstract}
The trend of using natural reinforcement has benefited the researchers in improving especially the mechanical properties, at the same time; it has helped also in reducing the cost, better bio- degradability, natural look to the component being prepared. The present research article describes the work carried out on natural fiber - pineapple fiber in combination with - E Glass fabrics with two different aerial densities $(200 \& 400 \mathrm{gm})$ being reinforced with epoxy a thermosetting resin to form hybrid at different material composition. The laminates made out of hybrid composites were fabricated by hand layup technique. The mechanical characterization of these hybrids reveals that the strength in tensile, impact and shear mode for P-G-E composite with EGlass fabric of $200 \mathrm{gsm}$ aerial density has increased. However, in three-point bend and indentation modes, the P-G-E hybrid with E-Glass fiber of $400 \mathrm{gsm}$ aerial density showed the highest flexural strength as well as hardness. Scanning electron microscopic images of failed samples under tensile loading were taken to highlight the fracturedareas.
\end{abstract}

Key Words: Pineapple, Glass fiber, Epoxy, Hybrid, Mechanical Characterization.

\section{INTRODUCTION}

Most of the industries are trying to find solutions for better eco-friendly materials by relying on natural resource, such as plant. As we are depending more upon the purely polymer based materials, which are very difficult to recycle or dispose and non-degradable once. These materials can affect the environment in various ways which may lead to an imbalance in nature. To reduce negative effects of such materials, many researchers are exploring the possible use of natural reinforcements. Natural reinforcement's exhibits good physical and mechanical properties, so they can be used in various fields - infrastructure, automotive, furniture, packaging biomedical, etc[1].

The major sources for natural reinforcement are from plants, namely cotton, kenaf, jute, hemp, sisal, pineapple, flax, coir etc. Among them, the pineapple leave fiber is one of the mostabundantly available in Mother Nature, as it is a natural reinforcing fiber on which very lesser studies has been carried out so for. The simple advantage of using the natural fibers is that they posses lower density when compared with polymer based materials. The greater reward of using natural fibers is that they inhibit light weight, bio-biodegradable, cheap, easily available, non toxic and more over they are renewable resources that can sustainable supply at least processing expenditure. Many researchers and scientists are showing more interest to explore possible ways of processing and synthesizing the natural fibers for better future through improved mechanical and physical properties when compared with synthetic fibres $[2,15]$.

Even though the natural fibers have so much desired properties, still it remains a challenge or drawback, that it inhibits high moisture absorption capacity, prone to chemical environments by which its surface properties may be declined, but at the same time using polymer based fibers can really impact the nature. The selection of pineapple leave fiber in the study has its own importance; this natural fiber is derived from its leaves of tropical fruit pineapple. The pineapple leaves are considered to be a waste which is being used for producing natural fibers. The pineapple fiber's chemically composed of cellulose, lignin, and ash. Pineapple fibers inherit good mechanical properties when added with polymer reinforced composites[3].

Pineapples are naturally hydrophilic when exposed to elevated temperatures. It can be treated by various chemical agents to reduce the moisture uptake and make it more reliable with improved mechanical properties. The use of natural fibers has lead to formation of green composites which shows better strength to weight ratio and ease compactness. One of the problems of natural fibers is that they improperly bonds with adherents which leads to poor load transfer between fiber and matrix, this problem can be overcome by surface modification treatments and establish good adhesion [4]. Many research indicates that polymers namely thermosets and thermoplastics can be used to reinforce the natural fibers to produce compatibility. When it comes to use ofsynthetic fibers namely glass fibers, they are costlier and density is high when compared with natural fibers, so many researchers are now focusing on the replacing partially glass fibers with natural one's, as they exhibit bio-degradability [5, 13, $14,15,16]$.

The natural reinforcements are commonly used with polymer matrix to produce composites with advantages of good mechanical properties which leads in applicable for various engineering applications. The major polymer matrix used commonly in industries is thermosets, that to epoxy resins with different grades exhibits well corrosion resistant, lower shrinkage, adhesion etc [6]. It is very difficult to expect remarkable properties in natural fibers itself, so it better to go for hybridization especially with glass fiber which can coexist easily with natural fibers and provide improved mechanical abilities in the material system [7] .

By getting insight on the above studies, the aim of this 
research is to develop hybrid composites, which can show better properties such as lightweight, cost-effective, and better performance when pineapple leaf fibres and GF as used as reinforcements with epoxy thermosetting polymer matrix. Employing pineapple leaf fibers in most favorable ratio and content with synthetic fibers of the hybrid fibres were assessed in order to achieve the optimum physical and mechanical properties.

\section{MATERIALS AND METHODS MATERIALS}

Pineapple leave fibers in Plain weave form was procured from Go Green products, Chennai, Tamil Nadu, India with aerial density of $400 \mathrm{gsm}$ having fiber diameter of $0.4 \mathrm{~mm}$, Glass fiber and fabric with aerial density of 400 and 200 gsm were procured from Suntech fibers, Bangalore,

,Karnataka, India. The thermosetting resins namely epoxy resin of grade Lapox L-12 and $\mathrm{h}$ hardener K-6 was supplied by Atul India Ltd., Gujarat, India [19].

\section{FABRICATION}

Hand Layup Technique [14] was followed to fabricate the hybrid composites. The epoxy and hardner was mixed at the proportion of 100:10 at room temperature. The hybrid laminates were prepared at different fiber stacking sequence as shown in figure 1 . The laminates were produced at specific dimensions - 300 x 300x $5 \mathrm{~mm}$ and allowed to cure at room temperature. Table 1 shows the composition of hybrid laminates fabricated.

\begin{tabular}{|c|c||c|}
\hline Glass Fiber (400 gsm) & Glass Fiber (200 gsm) & Glass Fiber (400 gsm) \\
Pineapple Fiber
\end{tabular}

Figure1. Stack Sequence of Hybrid Laminates

Table1. Composition of hybrid laminates fabricated

\begin{tabular}{|c|c|c|c|c|}
\hline SampleCode & $\begin{array}{l}\text { Glass Fiber } \\
(400 \mathrm{gsm}) w \mathrm{t} \%\end{array}$ & $\begin{array}{l}\text { Glass Fabric } \\
(200 \text { gsm) wt\% }\end{array}$ & $\begin{array}{l}\text { Pineapple Fiber } \\
(400 \text { gsm) wt } \%\end{array}$ & $\begin{array}{l}\text { Epoxy } \\
\text { wt } \%\end{array}$ \\
\hline P1 & 30 & 0 & 30 & 40 \\
\hline P2 & 0 & 30 & 30 & 40 \\
\hline P3 & 15 & 15 & 30 & 40 \\
\hline
\end{tabular}

\section{MECHANICAL CHARACTERIZATIONS}

Tensile test was carried out as per ASTM D 638 [10] using computerized universal testing machine Kalpak - 100 KN capacities to record load vs displacement keeping the crosshead speed of $5 \mathrm{~mm} / \mathrm{min}$ and span length of $80 \mathrm{~mm}$ to evaluate the tensile properties. The three point bending was done with accordance to ASTM D790 [11] maintaining the span length of 70 mm and crosshead speed of $2.5 \mathrm{~mm} / \mathrm{min}$ to assess flexural properties. The Interlaminar shear test was conducted as per ASTM D2344 [12] with crosshead speed of $1.5 \mathrm{~mm} / \mathrm{min}$ and span length of $40 \mathrm{~mm}$. The Charpy Impact test according to ASTM D256 [13] was performed using Instron Pendulum Tester at the striking rate of $3.5 \mathrm{~m} / \mathrm{s}$ to record the impact strength of the hybrid samples and hardness of samples were known by Micro-hardness (Shore-D) by using a Durometer in accordance with ASTM-D 2240 [15]. All the samples were dried in the oven at $30 \mathrm{C}$ temperature after been cut using Abrasive Jet Machining to ensure accurategeometry.

RESULTS AND DISCUSSION

The specimens were subjected to various mechanical loading and the obtained results s are shown in the table 2 indicating the mechanical properties of hybridcomposites.

Table2. Mechanical Properties of Hybrid Composites

\begin{tabular}{cccccccc}
\hline $\begin{array}{c}\text { Sample } \\
\text { Code }\end{array}$ & $\begin{array}{c}\text { Ultimate } \\
\text { Tensile } \\
\text { Stress } \\
(\mathbf{M P a})\end{array}$ & $\begin{array}{c}\text { Tensile } \\
\text { Modulus } \\
(\mathbf{M P a})\end{array}$ & $\begin{array}{l}\text { Flexural } \\
\text { Strength } \\
(\mathbf{M P a})\end{array}$ & $\begin{array}{l}\text { Flexural } \\
\text { Modulus } \\
(\mathbf{M P a})\end{array}$ & $\begin{array}{c}\text { Interlaminar } \\
\text { Shear } \\
\text { Strength } \\
(\mathbf{M P a})\end{array}$ & $\begin{array}{c}\text { Impact } \\
\text { Strength } \\
(\mathbf{J} / \mathbf{m})\end{array}$ & $\begin{array}{c}\text { Shore-D } \\
\text { Hardness }\end{array}$ \\
\hline P1 & 68.17 & 702.80 & 99.44 & 5738.43 & 7.93 & 223.6 & 70 \\
P2 & 65.48 & 675.01 & 119.24 & 10762.25 & 6.88 & 114.9 & 82 \\
P3 & 66.48 & 671.55 & 113.99 & 8574.25 & 7.20 & 164.9 & 89 \\
\hline
\end{tabular}




\section{TENSILE PROPERTIES}

The tensile test result shown in table 1 indicates that the ultimate tensile stress and tensile modulus of sample code $\mathrm{P} 1$ has $68.17 \mathrm{MPa}$ and $702.80 \mathrm{MPa}$ maximum when compared to others. The laminate with 400 gsm density in combination with pineapple leave fiber reinforced epoxy composite has shown good resistance to tensile loading. This is the clear sign of good bonding between matrix and reinforcements taken place during fabrication and proper load transfer has taken place from matrix system to especially the pineapple leave fibers $[16,3,4.5 .7,11,12]$.

\section{FLEXURAL PROPERTIES}

The flexural test result shown in table 1 indicates that the flexural strength and flexural modulus of sample code P2 has 119.24 $\mathrm{MPa}$ and 10762.25 $\mathrm{MPa}$ good enough, when compared to others. The laminate with 200 gsm density in combination with pineapple leave fiber reinforced epoxy composite has shown good resistance to flexural loading. The three point bending load on the sample code 2 showed the breaking of the matrix first and followed by fiber cracking. The sample after the test was carefully examined, which revealed that, when load was acting in perpendicular direction, the top layer fiber may have undergone the compressive deformation and bottom layer would have stretched out leading to fiber breakage $[16,3,4,5,7,18$, 19].

\section{INTERLAMINAR SHEAR STRENGTH PROPERTY}

The ILLS test result shown in table 1 indicates that the interlaminar shear strength of sample code P1 has 7.93 $\mathrm{MPa}$ quite high, when compared to others. The laminate with 400 gsm density in combination with pineapple leave fiber reinforced epoxy composite has shown good resistance to shear loading $[11,12]$.

\section{IMPACT PROPERTY}

The Charpy Impact test result shown in table 1 indicates better impact strength of sample code P1 has $223.6 \mathrm{~J} / \mathrm{m}$ when compared to others. The laminate with $400 \mathrm{gsm}$ density in combination with pineapple leave fiber reinforced epoxy composite has shown good resistance to impact loading. The impact load delivered by the pendulum at $3.5 \mathrm{~m} / \mathrm{s}$ striking speed to the sample code 1 showed better, this may be due to lower voids presence in the sample in the fabrication time and also it seems that, the pineapple fiber would have resisted the suddenly applied load to show better impact energy $[3,4,5,10,11,12]$.

\section{HARDNESS PROPERTY}

The Shore-D hardness test result shown in table 1 indicates that the hardness value of sample code P3 has 89 reasonably superior when compared to others. The laminate with 200 and 400 gsm density in combination with pineapple leave fiber reinforced epoxy composite has shown good resistance to micro-indentation. This resistance in the sample code 3 has shown good surface hardness due to better surface finish and quality curing of the laminates [12].

\section{SEM FRACTOGRAPHY OF HYBRID COMPOSITES}

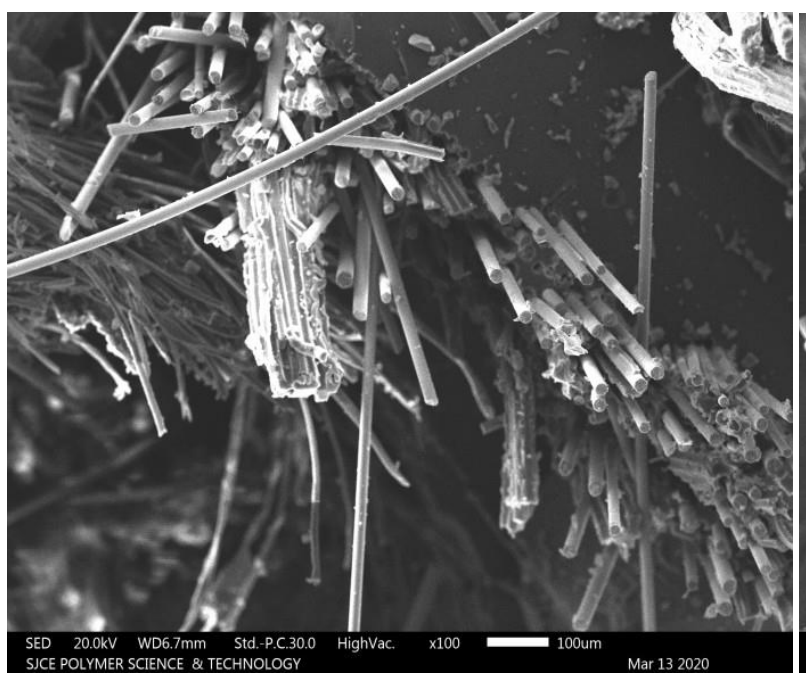

(a)

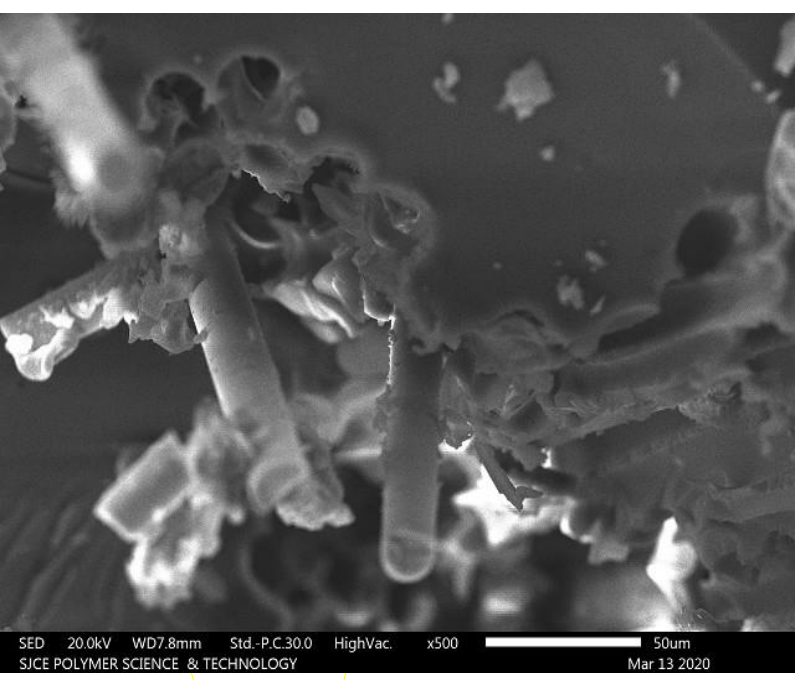

(b) 


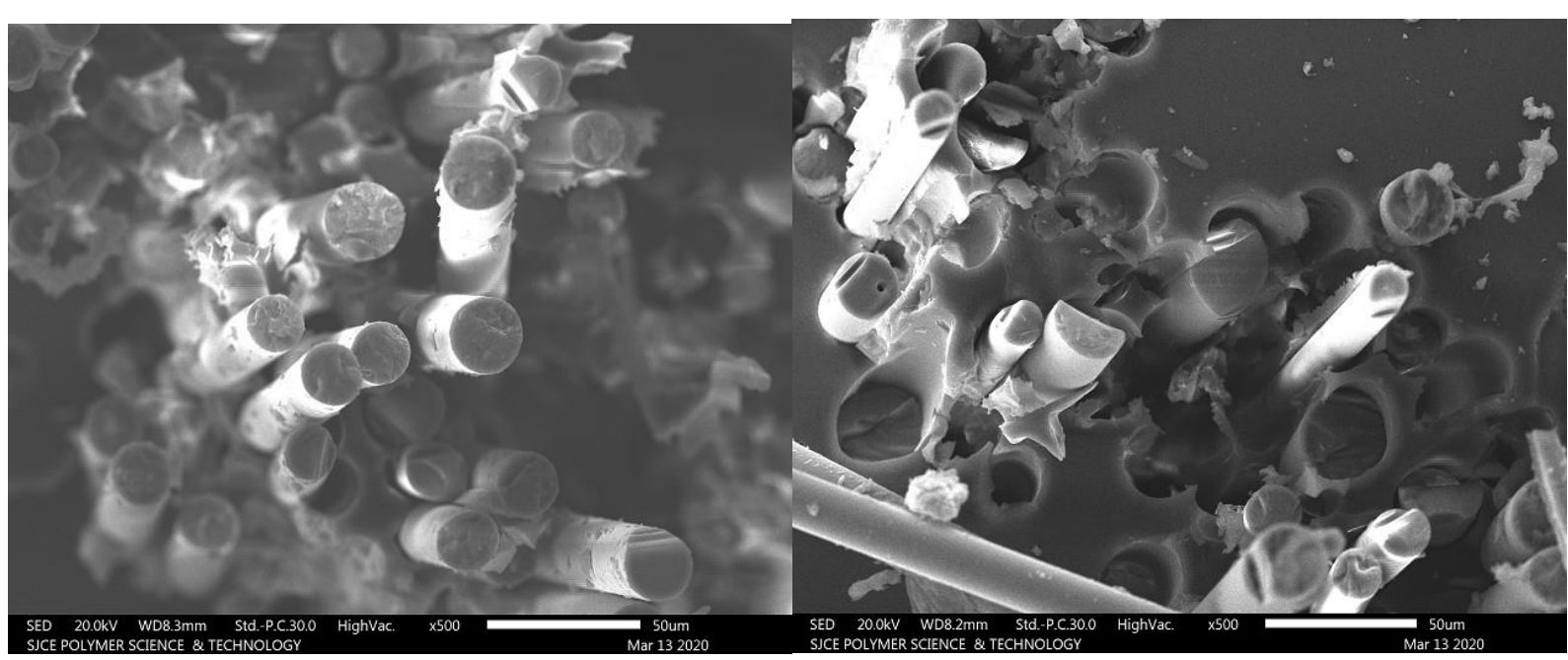

(c)

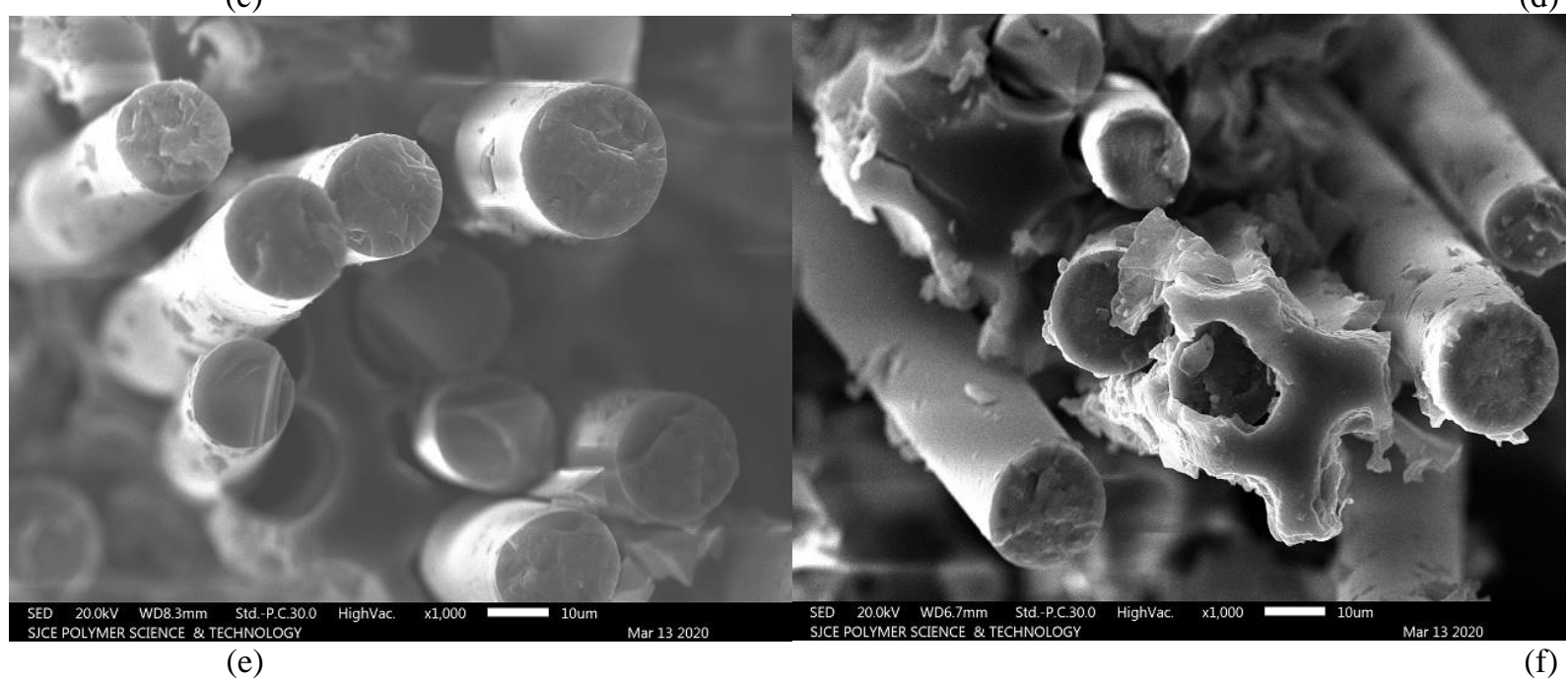

Figure2. SEM images of Tensile Fractured Specimen of Sample code P1

SEM images were taken on tensile fractured sample code P1 to investigate its failure area, to understand the level of bonding between glass fiber and pineapple leave fiber with epoxy and an attempt to interpret the result of tensile strength obtained under tensile loading [18, 19]. SEM pictures of sample code P1 for tensile fractured specimen are shown in figure 2 (a-e) with glass fiber distribution with pineapple leave fiber linked to epoxy [18, 19]. From the figure 2 (a-b), we can observe clear breaking between glass fibers and pineapple leave fibers, but it seems that pineapple leave fiber has been sheared under tensile loading and in general, mechanical abilities of composite depends on the fiber weight percentage with the matrix and effective bonding each other [18, 19]. Figure 2 (c-d) indicates some fibers been pulled out from the matrix, thus a good sign of good adhesion.

It is understood that, due higher percentage fiber been present in the material system, fibers would have be taken more longitudinal load which has directed towards increased tensile strength and modulus $[18,19]$.. Figure 2 (d-f) depicts clean fiber fracture /pull out at vey lower levels which is advantageous for fibers/matrix interfacial adhesion would have been quite strong enough with on other $[18,19]$.

\section{CONCLUSION}

Developing eco-friendly composites has been always a challenge, moving in this direction an attempt has been made to fabricate the Pineapple leave fiber with glass fiber reinforced epoxy hybrid composites by hand layup method and its mechanical characterization has been carried out as per ASTM standards [19]. Following are the conclusions drawn from the results obtained after the tests.

$\square \quad$ Tensile strength of the hybrid composite with $30 \%$ of glass and $30 \%$ pineappleleaf fiber wt $\%$ both having $400 \mathrm{gsm}$ densities. This would really call for a good fiber-matrix adhesion and efficiently the load distribution over the fibers.

$\square \quad$ Maximumflexuralstrengthcanbenoticedathybridco mpositesamplecodeP2,thisis because of glass fiber with 200 gsm density has fiber count per strand is more and closely aligned with each other.

$\square \quad$ Interlaminarshearstrengthofhybridcompositesseems tobeverylow; thepineapple leaf fiber could not contain the shear load as they are natural fiber with lesser capacity to withstand the tear.

$\square \quad$ CharpyimpactstrengthofhybridwithsamplecodeP1h asshowngoodresistanceto suddenly applied load 
due to presence of glass fibers, as natural fibers lack impact property.

Shore-

DhardnessofthehybridwithsamplecodeP3showsbett erhardnessduehigher percentage of glass fiber and good matrix adhesion, which would have covered up the tiny gaps exist between the pineapple leaf fibers and reduce vacant areas.

SEM photo's depicts the possible fracture mechanisms namely fiber pullout,fractured fibers, matrix breakage, fiber/matrix interaction directing towards the performance of the hybrid composites $[18,19]$.

\section{REFERENCES}

[1] Bartolome, A.P., Ruprez, P. And Prieto, A.. (1995) Polysaccharides from Pineapple Cell Walls. Journal of Agricultural and Food Chemistry, 43, 608-612. http://dx.doi.org/10.1021/jf00051a010.

[2] Musig, J.J. (2010) Industrial Applications of Natural Fibers. Shivarajah, M. And Kandasamy, S. (2010) Characterization of natural fibers as concrete composites for structural applications. I National Journal of Materials and Product Technology, 36, 385-395.

[3] Devi LU, Bhagavan SS, Thomas SL. Mechanical properties of pineapple leaf fiber-reinforced polyester compounds. Journal of Applied Polymer Science. May 31, 1997; 64 (9): 1739-48.

[4] Arib RMN, Sapuan SM, Ahmed MMHM, Parida MT, Zaman HMDK (2006) Mechanical properties of pineapple leaf fiber reinforced polypropylene compounds. Mater Des 27: 391-396. https: // doi. org / 10.1016 / j.matde s.2004.11.009.

[5] Barcoula NM, Alcock B, Cabrera NO, Peez T. Dynamic mechanical analysis of pineapple leaf/glass hybrid fiber reinforced polyester compounds. Polymer Composites 2008; 16 (2): 101-13. https://doi.org/10.1002/pc.

[6] John MJ and Anandjiwala RD. Recent developments in the chemical modification and properties of natural fiberreinforced composites. Polym Compos 2008; 29: 187-207.

[7] Uma Devi L, Bhagavan ST SS. Dynamic mechanical analysis of pineapple leaf / glass hybrid fiber reinforced polyester compounds. Polym Compos 2010; 31: 956-65. https://doi.org/10.1002/pc.20880.

[8] Mohammed AR, Sapuan SM, Shahjahan M, Khalina A. Effects of simple abrasive comb and preconditioning treatments on the properties of pineapple leaf fibers (PAF) and puff-vinyl ester combined adhesives. PolymPlast Technol Eng 2010; 2559. https: //doi.org/10.1080/03602559.2010.482072.

[9] Aji IS, Jainuddin ES, Khairul MD, Abdan K, Sapuan SM. High density polyethylene electron beam crosslinking reinforced with pineapple / kenaf leaf fiber hybridized with and without crosslinking agents.JReinfPlast Compos 2011; 30 (21): 182738. https://doi.org/10.1177/0731684411428776.

[10] Kabir MM, Wang H, Law KT, Cardona F, Aravindan T. Mechanical properties of chemically treated jute fiber reinforced sandwich compounds. Compos B Eng 2012; 43: 159-69.

[11] Aji IS, Jainudeen ES, Abdan K, Sapuan SM, Khairul MD. Mechanical properties and water absorption behavior of a hybridized kenaf / pineapple leaf fiber-reinforced high-density polyethylene compound. J Compos Mater 2013; 47 (8): 97990. https://doi.org/10.1177/0021998312444147.

[12] Hariwongsanupab N, Thanawan S, Amornschai T, Wallat MF, Mouginin K (2017) Improvement of the mechanical properties of the small pineapple fiber reinforced natural rubber by mixing it with acrylonitrile butadiene rubber. Polym's Proof 57: 94-100. https: //doi.org/10.1016/j.polymertes ting.2016.11.019.

[13] Sheikh MD Fadzullah SH, Mustafa ZD, Ramli SNR, Jacob Q, Mohammed Yousaf AF. A preliminary study on the mechanical properties of continuous elongated pineapple leaf fiber reinforced PLA biocomposites. Key Eng Mater 2016; 694 (December): 18-22

[14] Lobo MG, Siddique M. General description of pineapple production, post-harvest physiology, processing and nutrition In: MGL, Paul RE, editors. Pineapple Technology Manual: Science, Processing and Post-Harvest Nutrition. John Wiley \& Sons, Ltd .; 2016. https://doi.org/10.1002/9781118967355.ch1.

15] Cellphone Showroom Pickering, M.G.A. Efendi, T.M. Le, A review of recent developments in natural fiber composites and their mechanical performance, Compos. Part A Appl. Science. Manuf 83 (2016) 98-112. doi: 10.1016 j.compositesa.2015.08.038.

[16] TaveechaiAmornsai, Editor-Vijay Kumar Thakur, Chapter 12 Pineapple Leaf Fibers: High Potential Reinforcement for Green Rubber and Plastic Composites, Handb Compose Renew Matter, 289-305, ISBN 978-1-119-22362-7.

[17] Rhea, J. and Amrita, E.K. (2018) Experimental study on RCC beams reinforced with pineapple fiber. International Journal of Engineering Research and General Science, 6, 16.

[18] Asim M, Parida MT, Saba N, Javid M, Alothman OY, Nasir M, Almutairi ZD. Thermal, physical properties and combustion of phenolic hybrid compounds of silane-treated kenaf / pineapple leaf fibers. Composition Structure 2018; February: https://doi.org/10.1016/j.compstruct.2018.06.068.

[19] Hanafi ZDM, Abdan K, Norkhairunnisa M, AD Symes ZD, Ern LK. Effect of differential linear robot travel speed on the mass flowrate of Pineapple Leaf Fiber (PALF) Automatic Spray Up Composite. Compos B Eng 2018; 156: 220-8. https://doi.org/ 10.1016 / j.compositesb.2018.08.090. 